\title{
Primary care assessment instruments for patients at risk of, or with, persistent pain: opportunistic findings from a systematic literature review
}

This article was published in the following Dove Press journal:

International Journal of General Medicine

23 June 2009

Number of times this article has been viewed

\author{
Karen Grimmer-Somers' \\ Saravana Kumar' \\ Nic Vipond ${ }^{2}$ \\ Gillian Hall ${ }^{2}$ \\ 'Centre for Allied Health Evidence, \\ University of South Australia, \\ Australia; ${ }^{2}$ Accident Compensation \\ Corporation, Wellington, \\ New Zealand
}

Correspondence: Karen Grimmer-Somers Director, Centre for Allied Health Evidence, University of South Australia, City East Campus, North Tce, Adelaide 5000 , Australia

Tel +61883022769

Fax +6I 883022766

Email karen.grimmer-somers@unisa.edu.au
Background: Early identification in primary care settings of individuals with, or at-risk of, developing persistent pain, is important to limit development of disability. There is little information to assist primary care providers to choose or deliver relevant, efficient, and soundly constructed assessment instruments for this purpose.

Objective: We recently published the findings of a literature review, which produced a compendium of assessment instruments to identify adults with, or at-risk of developing, persistent pain of noncancer origin. This paper reports on instruments opportunistically identified during this review which may be appropriate to primary health care settings for early identification of such patients.

Results: One hundred sixteen potentially useful instruments were initially identified in the review, measuring pain severity, psychological distress, functional capacity, quality of life or multidimensional constructs of persistent pain. Following a series of steps, 45 instruments were shortlisted, with sound clinical utility and strong psychometric properties. Of these, 16 instruments were appropriate to primary health care settings because of simple wording, brief items, short administration time, and ease of scoring.

Conclusion: No one assessment instrument captured all constructs of persistent pain. The 16 instruments provide a broad choice for primary care clinicians to assist with early identification of adults at risk of, or with persistent pain.

Keywords: adults with persistent pain, primary health care assessment, early identification

\section{Background}

This paper reports on instruments which may be useful in primary health care settings for assessment of patients at-risk of, or with already established chronic or persistent pain. ${ }^{1}$ Primary care refers to health care provided in the community by medical, nursing and allied health professionals, which is often an individual's first point of entry into the health system. ${ }^{2}$ Time and resource constraints in primary care mean that assessment instruments should include few items (questions), simple language, efficient delivery, and ease of scoring. ${ }^{1-3}$

Although it is believed that 'persistent (chronic, or extended) pain' is "pain that exists beyond three months" Siddall and Cousins ${ }^{3}$ (p. 511), the timeframe for pain to change from acute to chronic varies from person to person. Standard assessment instruments have been reported as useful to predict disability, assess the likelihood of individuals with acute pain progressing to a more persistent pain state, and identify appropriate treatment strategies. ${ }^{4-6}$ Early identification of patients with persistent pain features in primary care settings facilitates timely referral for more comprehensive 
specialist health assessments. ${ }^{4-7}$ This may lead to timely intervention to circumvent potentially crippling disability from persistent pain, reduce medical and compensation costs, and increase return-to-work rates. ${ }^{8-12}$

The instruments outlined in this paper were identified during our recent systematic literature review. ${ }^{13}$ They reflect our understanding of the purpose of primary care assessment of individuals with pain, and the time and resource constraints of primary health care settings. The recent review ${ }^{13}$ was commissioned by the New Zealand Accident Compensation Corporation (ACC), the sole national 24-hour no fault injury insurer and rehabilitation purchaser.

\section{Methods}

\section{Purpose of the ACC-commissioned review}

The literature review ${ }^{13}$ identified psychometrically sound, clinically-useful assessment instruments for persistent pain of noncancer origin, for use by multidisciplinary healthcare teams or individual practitioners, or face-to-face or telephone delivery, in a range of health care settings and locations.

\section{Purpose of this paper}

This paper reports on persistent pain assessment instruments which were identified in the commissioned review and were considered appropriate for delivery in primary care settings.

\section{Literature review processes}

Our recent paper describes the search strategy, inclusion and exclusion criteria, assessment of methodological quality, steps taken to classify the identified assessment instruments for adults with persistent pain of noncancer origin, and the findings. ${ }^{13}$ The assessment instruments were classified in terms of pain severity, psychological distress, functional capacity, multidimensional constructs of persistent pain, and general health status/quality of life.

\section{Primary care instruments}

During the review, we opportunistically identified instruments which seemed appropriate to primary health care settings. These instruments were short and efficiently administered, and had simple language and scoring scales, and small numbers of items. Some also had score thresholds which indicated patients at risk of persistent pain. A summary of the literature review process, and the number of instruments included at each step of the review ${ }^{13}$ is provided in Figure 1.

\section{Results}

Table 1 lists the instruments which were considered appropriate for primary health care settings. Table 2 reports available cut-points that purport to identify patients at risk of, or with already developed symptoms of persistent pain.

\section{Pain severity}

\section{Unidimensional scales}

These single dimension pain severity scales quantify one pain dimension (severity), and comprise the Visual Analogue Scale (VAS), Visual Rating Scale (VRS), and Numeric Rating Scale (NRS). Their psychometric properties are well referenced. ${ }^{14,15}$ They use word descriptors of pain, and/or scores from 0-10, and form the basis for any pain assessment. On their own, these instruments provide insufficient detail to identify patients with persistent pain presentations and they should be coupled with other instruments for a comprehensive assessment.

The Chronic Pain Grade (CPG) measures persistent pain severity in domains of pain intensity, disability and persistence. It was developed for low back pain, headache and temporo-mandibular joint pain. ${ }^{16-19}$ It has strong psychometric properties of high intrarater reliability, internal consistency and construct validity compared to other instruments. ${ }^{16-19}$ Cutpoints are reported, and limited normative data is available for comparison $^{19,20}$ (see Table 2). Clinicians should be cautious when applying these values, as they may not be generalizable to patients groups other than those from which they were derived.

\section{Distinguishing between neuropathic and nonneuropathic pain}

The Leeds Assessment of Neuropathic Symptoms and Signs (LANSS) is a seven-item instrument comprising five self-report items and two sensory tests. ${ }^{21}$ It assesses pain as thermal, dysesthesia, paroxysmal, evoked and autonomic dysfunction. The self-report questions use Yes/No responses, and the sensory testing requires the primary care provider to physically test the patient. There are moderate scores for Kappa test-retest and Cronbach's alpha for internal consistency. ${ }^{21-27}$ Cut-points are reported for pain differentiation, with moderate sensitivity and specificity (see Table 2).

\section{Psychological distress}

\section{Anxiety, depression, and mood}

The Kessler Psychological Distress Scale (K10) is a widely reported two domain, 10-item measure of nonspecific psychological distress, intended to measure mood, anxiety and depression. ${ }^{28}$ It is appropriate for general use in primary health care as a mental health screening instrument, although 


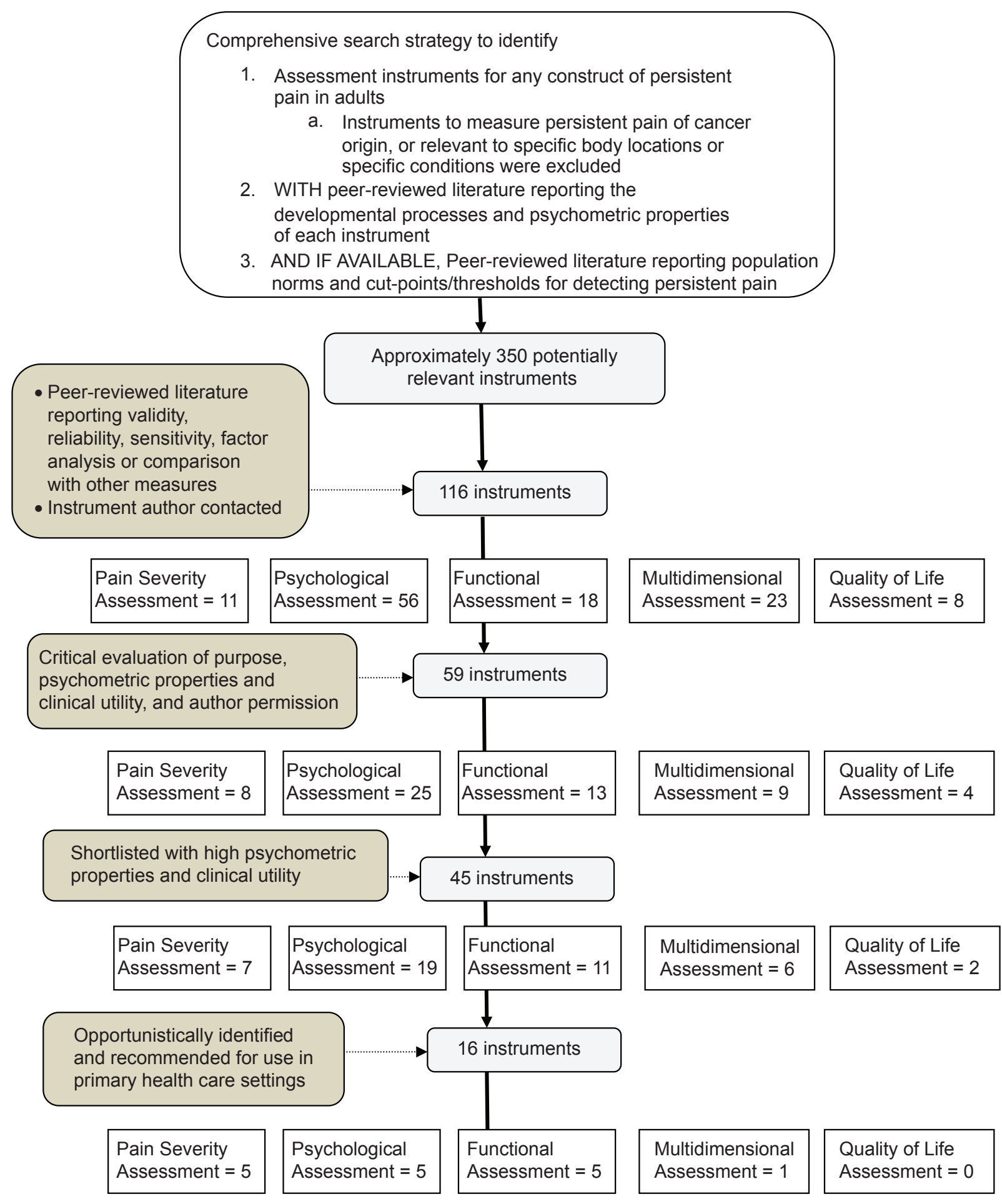

Figure I Consort diagram summarizing overall review processes and findings. ${ }^{13}$

it has not been specifically tested for persistent pain. It is reported as having cut-off scores with high sensitivity and specificity (area under the receiver operator characteristic [ROC] curve $>0.9$ ), and strong internal consistency and intrarater reliability. It has been used extensively in population surveys in Australia ${ }^{29}$ (see Table 2).

\section{Physiological manifestations of anxiety} and depression relative to persistent pain

The Modified Somatic Perception Questionnaire (MSPQ) is a 13-item measure of heightened somatic and autonomic awareness (clinically significant psychological distress) related to anxiety and depression. ${ }^{30}$ It has strong internal 
consistency and validity, and sound discriminant validity within different groups of pain sufferers. ${ }^{30,31}$ It links physical and psychological symptoms, and adds rare and important information to any assessment for persistent pain.

\section{Catastrophizing, negative thoughts, fear}

The Fear-Avoidance Beliefs Questionnaire (FABQ) is a 16-item, work-focused measure of patients' beliefs about how physical activity and work affect their pain. ${ }^{32,33}$ The developmental literature for this instrument reports high intratester reliability and test-retest, high internal consistency, and sound criterion and construct validity, which was tested against work time lost in the last 12 months, self-reported disability and poor behavioral performance. The FABQ is moderately correlated with the MSPQ, and highly correlated with the Tampa Scale for Kinesiophobia (see next instrument). ${ }^{32}$ There are published cut-points for the FABQ physical activity and work subscales (see Table 2). ${ }^{34,35}$ An alternative instrument to measure fear and catastrophizing is the Tampa Scale for Kinesiophobia short form (TSK_11), which has 11 items. ${ }^{36}$ It is reported as having high intrarater reliability and internal consistency, and moderate sensitivity and specificity (area under the ROC curve $>0.7$ ). It is sensitive to differences between health conditions and interventions. ${ }^{36}$ It has been validated in a number of languages.

\section{Behavioural change readiness}

The Pain Self Efficacy Questionnaire (PSEQ) is a 10-item instrument which measures pain cognition and self-confidence in performing functional and social activities, despite the presence of pain. ${ }^{37}$ It has reports of high intrarater reliability, internal consistency and stability on retest.

\section{Functional performance}

Occupational focus

The Occupational Role Questionnaire (OccRQ) measures aspects of occupation and pain. It is an eight-item, two-domain instrument which tests attitudes to returning/remaining at work by assessing productivity and satisfaction. ${ }^{38}$ The OccRQ has strong evidence of test-retest reliability and high internal consistency, and is moderately correlated with pain intensity (VAS).

\section{General function}

Two instruments which were identified for assessing this construct were developed by the same research group (FACS, RADLS), and both are useful. They are strongly correlated, and have high internal consistency. The Functional Abilities Confidence Scale (FACS) measures confidence with general functional activities, related to movements and postures affected by low back pain. ${ }^{39}$ The Resumption of Activities of Daily Living Scale (RADL) measures self-reported

Table I The instruments considered useful for primary health care settings, including instrument purpose, acronyms and relevant references

\begin{tabular}{|c|c|c|c|}
\hline Pain severity & Psychological distress & Functional capacity & $\begin{array}{l}\text { Multidimensional } \\
\text { constructs }\end{array}$ \\
\hline $\begin{array}{l}\text { Pain Severity (Unidimensional } \\
\text { Scales: Numeric Rating Scale,Visual } \\
\text { Analogue Scale,Visual Rating Scale) } \\
\text { [NRS,VAS,VRS] }^{14,15}\end{array}$ & $\begin{array}{l}\text { Anxiety, Depression, Mood } \\
\text { (Kessler Psychological } \\
\text { Distress Scale }[\mathrm{KI} 0]^{27,28}\end{array}$ & $\begin{array}{l}\text { Prognosis for functional return } \\
\text { to occupation (Occupational } \\
\text { Role Questionnaire) } \\
{[\text { OccRQ }]^{38}}\end{array}$ & $\begin{array}{l}\text { General pain impact } \\
\text { (Glasgow Pain } \\
\text { Questionnaire) } \\
{[G P Q]^{46}}\end{array}$ \\
\hline $\begin{array}{l}\text { Chronic Pain Severity (Chronic Pain } \\
\text { Grade) [CPG] }{ }^{16-20}\end{array}$ & $\begin{array}{l}\text { Somatic manifestations } \\
\text { of anxiety and depression } \\
\text { (Modified Somatic } \\
\text { Perception Questionnaire) } \\
{[\text { MSPQ] }]^{2,30}}\end{array}$ & $\begin{array}{l}\text { Confidence in function } \\
\text { (Functional Abilities } \\
\text { Confidence Scale) }[\mathrm{FACS}]^{39}\end{array}$ & \\
\hline $\begin{array}{l}\text { Differentiating between neuropathic } \\
\text { and nonneuropathic pain (Leeds } \\
\text { Assessment of Neuropathic } \\
\text { Symptoms and Signs) [LANSS] }{ }^{21-26}\end{array}$ & $\begin{array}{l}\text { Fear of Movement } \\
\text { (Fear-Avoidance Beliefs } \\
\text { Questionnaire) }\left[\text { FABQ], }{ }^{31,32}\right. \\
\text { (Tampa Scale for } \\
\text { Kinesiophobia (short form) } \\
{[\text { TSK_II }]^{36}} \\
\text { Pain self-efficacy } \\
\text { (Pain Self Efficacy } \\
\text { Questionnaire) } \\
{[\text { PSEQ }]^{37}}\end{array}$ & $\begin{array}{l}\text { Interference with daily function } \\
\text { (Pain Disability Index) [PDI] } \\
\text { Patient-centred assessment } \\
\text { of function (Patient-Specific } \\
\text { Functional Scale) [PSFS] }{ }^{43-45}\end{array}$ & \\
\hline
\end{tabular}


resumption of usual daily activities estimating confidence regarding return to usual activities. ${ }^{40}$ An alternative instrument relevant to assessing general function is the Pain Disability Index (PDI), which estimates impact on everyday activities and relationships. ${ }^{41}$ It is a measure of pain-related interference with role functioning, using domains of family/ home responsibilities, recreation, social activity, occupation, sexual behavior, self-care and life-support activity. It is reported to be sensitive to differences between patients with a range of different health conditions. ${ }^{41}$

Table 2 Cut off scores/thresholds

\begin{tabular}{|c|c|}
\hline Instrument & Scores \\
\hline \multicolumn{2}{|l|}{ Pain severity } \\
\hline Unidimensional scales (VAS, NRS,VRS) & No cut off scores are available, although the higher the score, the more severe the pain intensity \\
\hline \multirow[t]{6}{*}{$\mathrm{CPG}^{19,20}$} & Grade 0 No pain problem (prior 6 months) \\
\hline & Pain free \\
\hline & $\begin{array}{l}\text { Grade I Characteristic pain intensity less than } 50 \text {, and less than } 3 \text { disability points Low } \\
\text { disability-low intensity }\end{array}$ \\
\hline & $\begin{array}{l}\text { Grade II Characteristic pain intensity of } 50 \text { or greater, and less than } 3 \text { disability points Low } \\
\text { disability-high intensity }\end{array}$ \\
\hline & $\begin{array}{l}\text { Grade III 3-4 disability points, regardless of Characteristic pain intensity High disability-moderately } \\
\text { limiting }\end{array}$ \\
\hline & $\begin{array}{l}\text { Grade IV 5-6 disability points regardless of Characteristic pain intensity High disability-severely } \\
\text { limiting }\end{array}$ \\
\hline LANSS $^{21}$ & $\begin{array}{l}\text { Cut-point of } 12 \text { is sensitive ( } 83 \%) \text {, and specific }(87 \%) \text { for differentiating between neuropathic } \\
\text { and nonneuropathic pain }\end{array}$ \\
\hline \multicolumn{2}{|l|}{ Psychological distress } \\
\hline \multirow[t]{5}{*}{$\mathrm{K} 10^{28,29}$} & KIO scores of: \\
\hline & 10-19 Likely to be well \\
\hline & 20-24 Likely to have a mild psychological disorder \\
\hline & 25-29 Likely to have a moderate psychological disorder \\
\hline & 30-50 Likely to have a severe psychological disorder \\
\hline MSPQ & $\begin{array}{l}\text { No cut off scores are available, although the higher the score, the more marked the general } \\
\text { somatic symptoms }\end{array}$ \\
\hline FABQ & $\begin{array}{l}\text { A cut-off score for the activity subscale }(>15) \text { is proposed to identify patients with significant } \\
\text { issues of fear avoidance. }{ }^{34} \mathrm{FABQ} \text { work subscale scores }>34 \text { are associated with an increased } \\
\text { risk of not returning to } \text { work }^{35}\end{array}$ \\
\hline TSK_II & No cut-off scores are reported. The higher the score the higher the level of fear of movement \\
\hline PSEQ & No cut-off scores are reported. The higher the scores, the stronger the self-efficacy beliefs \\
\hline \multicolumn{2}{|l|}{ Functional performance } \\
\hline OccRQ & No cut-off scores are reported. The higher the score, the lower the reported productivity or satisfaction \\
\hline FACS & $\begin{array}{l}\text { No cut-off scores are reported. The lower the score the less confidence an individual has in } \\
\text { performing functional activities }\end{array}$ \\
\hline RADL & $\begin{array}{l}\text { No cut-off scores are reported. Higher scores indicate higher likelihood for resuming activities } \\
\text { of daily living }\end{array}$ \\
\hline PDI & No cut-off scores are reported. The higher the score, the greater the person's pain-related disability \\
\hline PSFS & $\begin{array}{l}\text { Cut points are not appropriate for this instrument as it is a patient-specific assessment of } \\
\text { individual function }\end{array}$ \\
\hline \multicolumn{2}{|l|}{ Multidimensional constructs } \\
\hline GPQ & $\begin{array}{l}\text { The minimum score is } 0 \text { and interpreted no pain frequency or intensity, no difficulties coping } \\
\text { with pain, no emotional reaction to pain and no restriction of activities of daily living due to } \\
\text { pain). The maximum score is } 10 \text { and is interpreted as constant pain, maximum pain intensity, } \\
\text { extreme difficulty coping with pain, extreme emotional reaction due to pain or extreme } \\
\text { restriction of activities of daily living due to pain. No cut-off scores are reported. The higher } \\
\text { the score, the more bothersome the pain }\end{array}$ \\
\hline
\end{tabular}

Abbreviations: CPG, Chronic Pain Grade; FABQ, Fear-Avoidance Beliefs Questionnaire; FACS, Functional Abilities Confidence Scale; GPQ, Glasgow Pain Questionnaire; KI0, Kessler Psychological Distress Scale; LANSS, Leeds Assessment of Neuropathic Symptoms and Signs; MSPQ, Modified Somatic Perception Questionnaire; NRS, Numeric Rating Scale; OCCRQ, Occpational Role Questionnaire; PDI, Pain Disability Index; PSFS, Patient Specific Functional Scale; PSEQ, Pain Self Efficacy Questionnaire; RADL, Resumption of Activities of Daily Living Scale;TSK-I I,Tampa Scale for Kinesiophobia;VAS, Visual Analogue Scale;VRS,Visual Rating Scale. 


\section{Patient-specific instruments}

The importance of considering the patient's perspective when assessing function is highlighted by Kliempt and colleagues. $^{42}$ The Patient Specific Functional Scale (PSFS) is a simple, relevant clinical tool for eliciting, measuring, and recording patients' descriptions of their disabilities. ${ }^{43}$ It has strong evidence of construct validity, intrarater reliability, sensitivity, and specificity. ${ }^{44,45}$ It is reported as appropriate for, and sensitive to, a range of different health conditions.

\section{Multidimensional constructs}

The Glasgow Pain Questionnaire (GPQ) is a multidimensional measure of pain (assessing frequency, intensity, emotional reactions, ability to cope and restriction of daily activities). ${ }^{46}$ The GPQ anchors its pain interference descriptors in day-to-day activities and thus is useful for discussions between primary care providers and patients. It uses a logarithmic scale which provides a nonlinear scoring system to assess the effect of pain on daily function.

\section{Discussion}

This paper provides a resource for primary care providers which could increase the ease and frequency of early identification of patients with persistent pain presentations. The 16 instruments described in this paper provide choices to assess pain severity, psychological distress, functional capacity, and multidimensional constructs associated with persistent pain.

These instruments are primarily recommended for once-only administration to inform a broad primary care assessment, and to underpin referral to other health care providers specializing in comprehensive assessment for, and treatment of persistent pain. The primary care assessment scores could be shared between health care providers to quantify the affects of pain on the individual, and to provide baseline measures for subsequent use by specialist health care providers to chart change over time, and/or the effect of treatment. However, to date, there is a paucity of research which demonstrates the efficacy of any pain assessment instrument in primary care settings, and thus there is a need to evaluate whether these instruments are indeed useful in practical terms, to sensitively detect patients with persistent pain behaviors. Research is also required to test whether patients identified early by primary care providers as having persistent pain presentations and have better health and cost outcomes than those identified later. Pain presentations vary from patient to patient, and thus research is also required to identify which instruments are most useful in primary care to detect patients with different risk profiles for persistent pain. ${ }^{47}$

Given the high medical and workplace costs related to managing patients once persistent pain states have become established, ${ }^{8-12}$ primary care settings provide valuable opportunities to flag patients early, who may exhibit persistent pain presentations. ${ }^{2}$ Although persistent pain is believed to take up to 12 weeks to manifest, once acute pain has been experienced, patients' progress towards persistent pain states is individual. ${ }^{1,3,47}$ Thus patients at risk of progressing to persistent pain states could well be identified early by an alert primary care provider ${ }^{3,4,6}$ who is aware of the range of manifestations of persistent pain.

Our review found that no single assessment instrument measured all features of persistent pain. Thus primary care providers may need to administer more than one instrument to obtain a broad understanding of the characteristics of a patient potentially presenting with persistent pain. Even with only 16 instruments to choose from, busy primary health providers may be confused as to which one(s) to apply. The following section outlines an example of how several persistent pain assessment instruments might be applied by primary care providers who are using them for the first time.

1. Clinicians might start with a unidimensional pain severity scale (VRS, VAS, NRS) to set the scene about a patient's pain. There is no guidance regarding the level of pain severity which should be of concern, as in many cases chronic pain tends not to be severe, rather it is persistent and disabling. ${ }^{3,8,9}$ However use of a simple pain severity assessment instrument can open discussions with patients about their pain.

2. Clinicians might then apply a multidimensional pain measure, such as the GPQ ${ }^{46}$ to provide a broader overview of the patient's pain experience. This instrument asks a number of questions to which patients reply True/ False. A weighted numeric score is assigned to the all 'true' responses, and the scores are then summed to produce domain scores of frequency, intensity, ability to cope, emotional reaction and restriction of daily activity. Table 2 reports score interpretation.

3. Further assessment could include the K10 to measure general psychological distress states. ${ }^{28,29}$ Table 2 reports cut-off scores which are estimates of the prevalence of levels of psychological distress in an Australian population health survey (however these are not tested on patients with persistent pain). ${ }^{29}$ 
4. The Patient-Specific Functional Scale ${ }^{43,45}$ could then be applied to assist primary care providers to better understand patients' individual perspectives of the activities that are most constrained by their pain. This is a rare instrument which uses patient-generated examples of how they are affected by their pain, rather than examples of activities generated by researchers. After identifying up to five activities with which they have difficulties, patients then assign a score from $0-10$ to each activity, with a score of 10 being 'unable to perform the activity at the same level as before the injury/problem' ${ }^{43}$ The activities identified by patients provide valuable insights for primary care providers regarding what is important to patients. They would be concerned if patients reported high scores (high constraints) for any activity.

5. Additional primary care assessment instruments reported in this paper could then be chosen to measure other relevant aspects of pain presentation, psychological distress, or functional constraints such as concern regarding return to work.

The New Zealand ACC Persistent Pain Assessment Instrument Compendium provides details on all assessment instruments reported in this paper, as well as the other shortlisted instruments relevant for administration in secondary assessment settings. The Compendium includes copies of instruments, scoring systems, background references, and threshold cut-off scores (where available). The Compendium can be ordered online. ${ }^{48}$

\section{Conclusion}

Early identification of patients at risk of developing persistent pain is essential to ensure appropriate and timely intervention, and reduce avoidable individual, social, community and work-related costs. Primary health care providers who do not regularly use standard assessment instruments for such patients are encouraged to choose instruments from the list in this paper, or choose other instruments outlined in the NZ ACC Compendium. These instruments are valuable for standardizing the assessment process, and establishing baseline scores which could be shared with other health care providers involved in the patient's care.

\section{Disclosure}

The authors report no conflicts of interest in this work.

\section{References}

1. Cousins MJ. Persistent pain: a disease entity. J Pain Symptom Manage. 2007;33(2):S4-S10.

2. Keleher H. Why primary health care offers a more comprehensive approach to tackling health inequalities than primary care. Australian Journal of Primary Health. 2001;7(2):57-61.
3. Siddall PJ, Cousins MJ. Persistent pain as a disease entity: Implications for clinical management. Anesth Analg. 2004;99(2):510-520.

4. Bowling A. Research Methods in Health: Investigating health and health services. 2nd ed. Philadelphia, PA: Open University Press, Buckingham; 2002.

5. Streiner D. Clinimetrics vs psychometrics: an unnecessary distinction. J Clin Epidemiol. 2003;56(12):1142-1145.

6. Wind H, Gouttebarge V, Kuijer PP, Frings-Dresen MH. Assessment of functional capacity in the musculoskeletal system in the context of work, daily living and sport: a systematic review. J Occup Rehabil. 2005; 15(2):253-272.

7. Sackett DL, Straus SE, Richardson WS, Rosenberg W, Haynes RB. Evidence-based Medicine: How to practice and teach. London: Churchill Livingston; 2000.

8. Blyth FM, March LM, Nicholas M, Cousins MJ. Chronic pain, work performance and litigation. Pain. 2003;103:41-47.

9. Blyth FM, March LM, Brnabic AJM, Cousins MJ. Chronic pain and frequent use of health care. Pain. 2004;111:51-58.

10. Indahl A, Haldorsen EMH, Holm S, Reikeras O, Olav MD. Five-year follow-up study of a controlled clinical trial using light mobilization and an informative approach to low back pain. Spine. 1998;23(23): 2625-2630.

11. Blyth FM, March LM, Brnabic AJ, Jorm LR, Williamson M, Cousins MJ. Chronic pain in Australia. A prevalence study. Pain. 2001;89:127-134.

12. Blyth FM, March LM, Cousins MJ. Chronic pain-related disability and use of analgesic and health services in a Sydney community. Med $J$ Aust. 2003;179:84-87.

13. Grimmer-Somers K, Vipond N, Kumar S, Hall G. A review and critique of assessment instruments for patients with persistent pain. Journal of Pain Research. 2009;2:21-47.

14. Agency for Health Care Policy and Research. Acute Pain Management: Operative or medical procedures and trauma, Clinical Practice Guideline No. 1. Publication No. 92-0032. Rockville, MD: Agency for Health Care Policy and Research; 1992. p. 116-117.

15. Texas Cancer Council. Guidelines for treatment of cancer pain: The revised pocket edition of the final report of the Texas cancer council's workgroup on pain control in cancer patients. 1997. Cited 2006 October 11. Available from http://www.texascancercouncil.org/.

16. Von Korff M, Ormel J, Keefe FJ, Dworkin SF. Grading the severity of chronic pain. Pain. 1992;50(2):133-149.

17. Elliott AM, Smith BH, Smith WC, Chambers WA. Changes in chronic pain severity over time: the chronic pain grade as a valid measure. Pain. 2000;88(3):303-308.

18. Elliott AM, Smith BH, Hannaford PC, Smith WC, Chambers WA. Assessing change in chronic pain severity: the chronic pain grade compared with retrospective perceptions. Br J Gen Pract. 2002;52(477): 269-274.

19. Von Korff M, Jensen MP, Karoly P. Assessing global pain severity by self-report in clinical and health services research. Spine. 2000;25(24):3140-3151.

20. Dunn KM, Croft PR. Classification of low back pain in primary care: using "bothersomeness" to identify the most severe cases. Spine. 2005;30(16):1887-1892.

21. Smith CA, Wallston KA, Dwyer KA, Dowdy SW. Beyond good and bad coping: a multidimensional examination of coping with pain in persons with rheumatoid arthritis. Ann Behav Med. 1999;19(1): $11-21$.

22. Bennett M. The LANSS pain scale: the Leeds assessment of neuropathic symptoms and signs. Pain. 2001;92(1-2):147-157.

23. Backonja M. Need for differential assessment tools of neuropathic pain and the deficits of LANSS pain scale. Pain. 2002;98(1-2):229-230.

24. Bennett MI, Smith BH, Torrance N, Potter J. The S-LANSS score for identifying pain of predominantly neuropathic origin: validation for use in clinical and postal research. J Pain. 2005;6(3):149-158.

25. Benzon HT. The neuropathic pain scales. Reg Anesth Pain Med. 2005;30(5):417-421. 
26. Kaki AM, El-Yaski AZ, Youseif E. Identifying neuropathic pain among patients with chronic low-back pain: use of the Leeds assessment of neuropathic symptoms and signs pain scale. Reg Anesth Pain Med. 2005;30(5):422-428.

27. Orhan EK, Yucel A, Senocak M, Ertas M. The validation study results of LANSS pain scale. Agri-Istanbul. 2002;14(3):49-54.

28. Kessler RC, Andrews G, Colpe LJ, et al. Short screening scales to monitor population prevalence and trends in non-specific psychological distress. Psychol Med. 2002;32(6):959-976.

29. Andrews G, Slade T. Interpreting scores on the kessler psychological distress scale (K10). Aust N Z J Public Health. 2001;25(6):494-497.

30. Main CJ. The modified somatic perception questionnaire (MSPQ). J Psychosom Res. 1983;27(6):503-514.

31. Deyo RA, Walsh NE, Schoenfeld LS, Ramamurthy S. Studies of the modified somatic perceptions questionnaire (MSPQ) in patients with back pain. Psychometric and predictive properties. Spine. 1989;14(5):507-510.

32. Waddell G, Newton M, Henderson I, Somerville D, Main CJ. A fearavoidance beliefs questionnaire (FABQ) and the role of fear-avoidance beliefs in chronic low back pain and disability. Pain. 1993;52(2):157-168.

33. Crombez G, Vlaeyen JW, Heuts PH, Lysens R. Pain-related fear is more disabling than fear itself: evidence on the role of pain-related fear in chronic back pain disability. Pain. 1999;80(1-2):329-339.

34. Burton AK, Waddell G, Tillotson KM, Summerton N. Information and advice to patients with back pain can have a positive effect: a randomized controlled trial of a novel educational booklet in primary care. Spine. 1999;24(23):2484-2491.

35. Fritz JM, George SZ, Delitto A. The role of fear avoidance beliefs in acute low back pain: relationships with current and future disability and work status. Pain. 2001;94(1):7-15.

36. Woby SR, Roach NK, Urmston M, Watson PJ. Psychometric properties of the TSK-11: a shortened version of the Tampa scale for kinesiophobia. Pain. 2005;117(1-2):137-144.

37. Nicholas MK. The pain self-efficacy questionnaire: taking pain into account. Eur J Pain. 2007;11(2):153-163.
38. Kopec JA, Esdaile JM. Occupational role performance in persons with back pain. Disabi Rehabil. 1998;20(10):373-379.

39. Williams RM, Myers AM. Functional abilities confidence scale: a clinical measure for injured workers with acute low back pain. Phys Ther. 1998;78(6):624-634.

40. Williams RM, Myers AM. A new approach to measuring recovery in injured workers with acute low back pain: resumption of activities of daily living scale. Phys Ther. 1998;78(6):613-623.

41. Pollard CA. Preliminary validity study of the pain disability index. Percept Mot Skills. 1984;59(3):974

42. Kliempt P, Ruta D, McMurdo M. Measuring the outcomes of care in older people: a non-critical review of patient-based measures. III. Pain, physical disability and handicap, and social health instruments. Rev Clin Gerontol. 2000;10:235-244.

43. Stratford P, Gill C, Westaway M, Binkley J. Assessing disability and change on individual patients: a report of a patient specific measure. Physiother Can. 1995;47(4):258-263.

44. Chatman AB, Hyams SP, Neel JM, Binkley JM, et al. The patientspecific functional scale: measurement properties in patients with knee dysfunction. Phys Ther. 1997;77(8):820-829.

45. Westaway MD, Stratford PW, Binkley JM. The patient-specific functional scale: validation of its use in persons with neck dysfunction. J Orthop Sports Phys Ther. 1998;27(5):331-338.

46. Thomas RJ, McEwen J, Asbury AJ. The Glasgow pain questionnaire: a new generic measure of pain; development and testing. Int $J$ Epidemiol. 1996;25(5):1060-1067.

47. Aggarwal VR, McBeth J, Zakrzewska JM, Lunt M, Macfarlane GJ. The epidemiology of chronic syndromes that are frequently unexplained: do they have common associated factors? Int J Epidemiol. 2006;35(2): 468-476.

48. Accident Compensation Corporation. 2009. Accessed on June 3, 2009. Available from: http://www.acc.co.nz/.
International Journal of General Medicine

\section{Publish your work in this journal}

The International Journal of General Medicine is an international, peer-reviewed open-access journal that focuses on general and internal medicine, pathogenesis, epidemiology, diagnosis, monitoring and treatment protocols. The journal is characterized by the rapid reporting of reviews, original research and clinical studies across all disease areas.

\section{Dovepress}

A key focus is the elucidation of disease processes and management protocols resulting in improved outcomes for the patient.The manuscript management system is completely online and includes a very quick and fair peer-review system. Visit http://www.dovepress.com/ testimonials.php to read real quotes from published authors. 